\title{
Numerical Modelling of Slide-induced Bore-like Wave Propagation
}

\author{
Joongcheol Paik \\ Department of Civil Engineering, Gangneung-Wonju National University \\ 7 Jukheon-gil, Gangneung, Gangwon, 25457, South Koream \\ paik@gwnu.ac.kr
}

\section{Extended Abstract}

The debris flows occurred on steep slopes in the river and reservoir area may move down the subaerial slope and continue traveling underwater with generating hazardous impact water waves. The impulse wave typically involves a multiphase flow containing the solid-water mixture as non-Newtonian fluid due to slope failure, water in river and reservoir and air entrained from water splash generated during the impact. The complex interaction of the non-Newtonian debris flow and Newtonian water and air flows can significantly affect the propagation of subaqueous debris flow as well as the impact water wave. The resulting impact waves can be classified by cnoidal wave, solitary wave, sinusoidal wave and bore, depending on the ranges of governing parameters, such as impact velocity, impact angle, head thickness and bulk volume of debris flow and still water depth. Impulse wave induced by a debris-flow is numerically investigated using a CFD solver for the multiphase flow. The three-dimensional filtered Navier-Stokes equations are used for reproduces the propagation and interactions of water flow and non-Newtonian debris flow traveling along the slope and channel bottom. A multiphase volume of fluid method is employed for tracking of fluid interfaces of fluid phases. The governing equations are solved by a second-order-accurate finite volume methods implemented in the OpenFOAM open source toolkit [1]. The turbulent stresses in the Newtonian fluid flows are calculated by the wall-adapting local eddy viscosity model and the nonNewtonian behaviour of debris flow is computed by using a modified Hershel-Bulkley fluid model. The multiphase flow model is applied to reproduce the laboratory measurements of Heller and Hager [2] who experimentally investigated the propagation of impulsive bore-like wave with a considerable air cavity. The numerical result shows that the proper calculation of the rheological behaviour of debris flow both on the slope of 60 degree and underwater is important to accurately reproduce the impulse wave. The present model reasonably reproduces the development and propagation of impact wave and debris flow, while more advanced approach is required to resolve the air entrainment at the wave front and detrainment at the wave tail.

\section{References}

[1] H. Jasak, "OpenFOAM: Open source CFD in research and industry," Int. J. Naval Architecture and Ocean Engrg., vol. 1, no. 2, pp. 89-94, 2009.

[2] V. Heller and W.H. Hager, "Wave types of landslide generated impulse waves," Ocean Engineering, vol. 38, pp. 630640, 2011. 